Article

\title{
On-Line Detection of Voltage Transformer Insulation Defects Using the Low-Frequency Oscillation Amplitude and Duration of a Zero Sequence Voltage
}

\author{
Hongwen Liu ${ }^{1}$, Ke Wang ${ }^{1}$, Qing Yang ${ }^{2, *}$, Lu Yin ${ }^{2}$ and Jisheng Huang ${ }^{3}$ \\ 1 Electric Power Research Institute of Yunnan Electric Power Corporation, Kunming 650217, China; \\ liuhongwen@yn.csg.cn (H.L.); wangke03@yn.csg.cn (K.W.) \\ 2 State Key Laboratory of Power Transmission Equipment \& System Security and New Technology, \\ Chongqing University, Chongqing 400044, China; 20161113059@cqu.edu.cn \\ 3 Lincang Power Supply Company of Yunnan Electric Power Corporation, Lincang 677000, China; \\ huangxusheng@yn.csg.cn \\ * Correspondence: yangqing@cqu.edu.cn; Tel.: +86-137-0838-0265
}

Received: 17 January 2019; Accepted: 12 February 2019; Published: 15 February 2019

\begin{abstract}
The insulation degradation of a voltage transformer winding is not easy to find, but it may ultimately cause the transformer to explode, leading to accidents such as phase-to-phase short circuits. At present, power transformers, lightning arresters, and other equipment have on-line methods to detect the insulation state. However, there is no mature method for the on-line monitoring of voltage transformer winding insulation. In this study, a small current disturbance method based on a zero-sequence loop is proposed. The characteristic parameters of the low-frequency oscillation of zero-sequence voltage after a disturbance are used to evaluate the insulation state of the winding and detect faults. Theoretical modeling, simulation tests, and field tests show that when the insulation resistance of the voltage transformer winding is in the range $0-40 \mathrm{k} \Omega$, a low frequency oscillation of about $10 \mathrm{~Hz}$ can be detected on the zero-sequence voltage, and its amplitude and duration are proportional to the degree of damage to the insulation. This can hence be used as a criterion for the on-line detection of voltage transformer winding insulation defects.
\end{abstract}

Keywords: voltage transformer (VT); zero-sequence voltage; small current disturbance; on-line detection

\section{Introduction}

To prevent the ferromagnetic resonance of a voltage transformer during the operation of a non-effective grounding system of $35 \mathrm{kV}$ and below [1,2], the neutral point of the $\mathrm{Y}$ wiring voltage transformer is generally equipped with a harmonic elimination device [3,4], as shown in Figure 1. At present, the harmonic elimination device is generally a non-linear silicon carbide resistor. It is generally believed that the ferromagnetic resonance can be eliminated when the ratio of the resistance value $R$ of the primary harmonic elimination device to the excitation reactance $X_{m}$ of the voltage transformer at the rated line voltage is greater than 0.06 . The resistance of a primary harmonic elimination device of $10 \mathrm{kV}$ and below is above $60 \mathrm{k} \Omega$, and the resistance value of $35 \mathrm{kV}$ primary harmonic elimination device is above $150 \mathrm{k} \Omega$. At present, many suppression measures [5-12] have been proposed based on the mechanism of ferromagnetic resonance [13-19].

Fully insulated electromagnetic voltage transformers and semi-insulated electromagnetic voltage transformers are currentlyused in the distribution network. Fully insulated VT means that the main insulation between the primary winding and the secondary winding and the ground is subjected to a $100 \%$ power frequency test voltage. Semi-insulated VT is a single-phase voltage transformer where 
one end of the primary winding is directly grounded. The semi-insulated electromagnetic voltage transformer is low in cost, small in size and light in weight, and is widely used in distribution network systems of $35 \mathrm{kV}$ and below.

There is insulation between the two windings of the voltage transformer and between the winding and the core, so that there is electrical isolation between the two windings and between the winding and the core. According to the insulation type, the voltage transformer can be divided into dry type, cast type, oil immersed type and inflatable type. The insulating medium of dry voltage transformer is composed of ordinary solid insulating material such as insulating paper, glass ribbon and polyester film. Its structure is simple, there is no danger of fire and explosion, but the insulation strength is low. It is only suitable for indoor devices below $6 \mathrm{kV}$. The insulating medium of the cast voltage transformer is composed of epoxy resin or unsaturated resin mixed material. It has compact structure and convenient maintenance and it is suitable for indoor power distribution equipment of $35 \mathrm{kV}$ and below. The insulating medium of the oil-immersed voltage transformer is composed of insulating paper and insulating oil. It has good insulation performance and can be used for an outdoor power distribution device of $10 \mathrm{kV}$ or more. Inflatable voltage transformers are used in fully enclosed $\mathrm{SF}_{6}$ appliances.

A voltage transformer group equipped with a primary harmonic elimination device is prone to generating a short-time power frequency overvoltage at the neutral point ( $\mathrm{N}$ terminal), that is, at the tail end of the primary harmonic elimination device under the action of single-phase grounding (recovery), transmission overvoltage, lightning overvoltage, and operating overvoltage. The long-term effects of overvoltage will cause the insulation performance of the voltage transformer to gradually deteriorate until the insulation is destroyed completely and the transformer is damaged, as shown in Figure 2. The voltage transformer is connected to the bus. If the fuse cannot be blown quickly, the fault is not removed, and the transformer will explode in the switchgear, which will cause the bus to be short-circuited. The transformer is then impacted by the short-circuit current, which seriously affects the safe and stable operation of the power system.

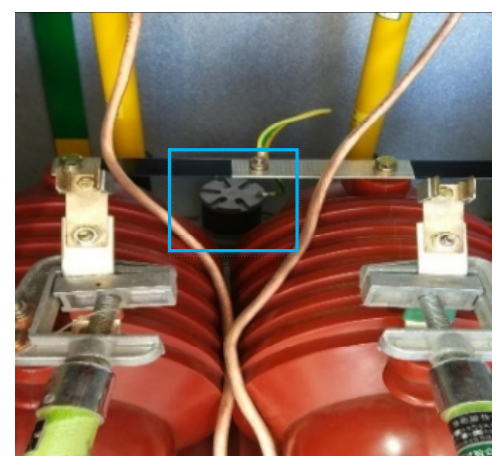

Figure 1. VT harmonic eliminator.
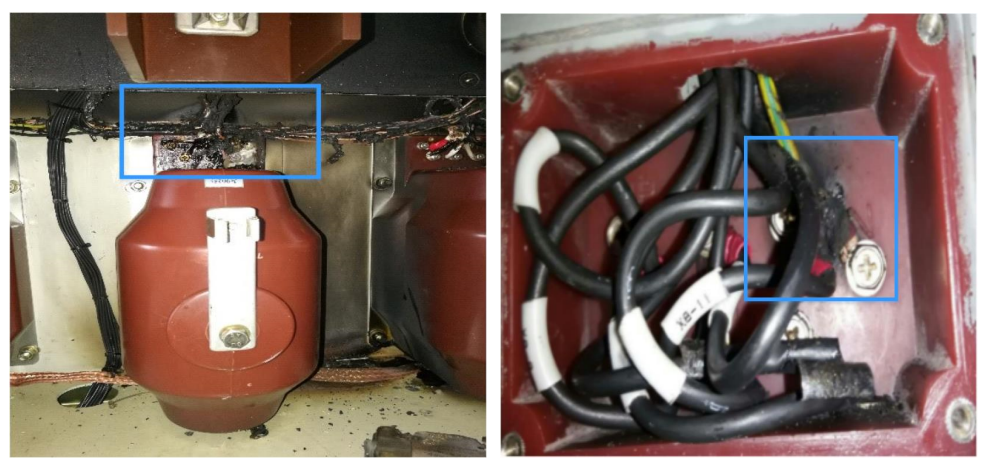

Figure 2. Damaged VT. 
Generally, deterioration of the internal insulation of a voltage transformer cannot be found easily. Because of the installation of the primary harmonic elimination device, the secondary voltage of the transformer is not abnormal, even the insulation is destroyed completely. Hence, in this paper, a small current disturbance using the zero-sequence circuit method is proposed to realize latent fault detection for winding insulation [20]. This method uses the characteristic parameters of the low-frequency oscillation of zero-sequence voltage after a disturbance to evaluate the insulation state of the winding, and its use will reduce the number of power grid accidents caused by transformer explosion.

\section{Small Current Disturbance of a Zero-Sequence Circuit}

In the actual operation of a transformer, the vector sum of three-phase voltage is not zero. In the method in this study, a short-circuit switch is connected at both ends of the open triangular winding of the voltage transformer and a small current disturbance $\Delta i[21,22]$ is applied to the zero-sequence circuit. The short-circuit switch is closed for a certain time and then opened; the three-phase voltage waveform of the measuring winding is collected and zero-sequence voltage waveform is synthesized. Then, the insulation state is evaluated using the zero-sequence voltage when the short-circuit switch is closed and the fluctuation of the zero-sequence voltage after the short-circuit switch has been opened. The principle of this method is shown in Figure 3.

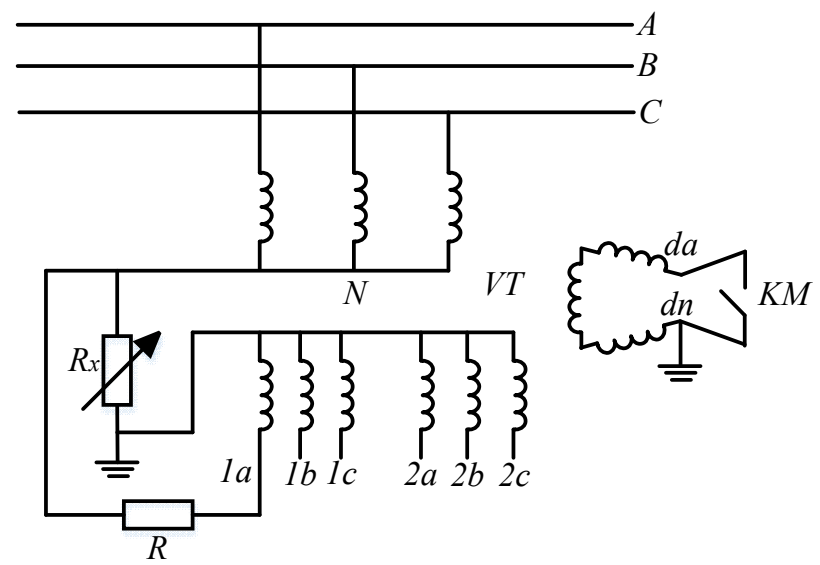

Figure 3. Scheme for the online detection of VT insulation.

In Figure 3, labels $1 a, 1 b$, and $1 c$ indicate the secondary ends of the transformer; $2 a, 2 b$, and $2 c$ are the measured windings; $\mathrm{KM}$ is a shorting switch; $d a$ and $d n$ are the $\mathrm{A}$ and $\mathrm{N}$ ends of the open triangular winding of the voltage transformer; $R_{x}$ is a harmonic elimination device; and $R$ is the insulation resistance between the voltage transformer (VT) ground $N$ end and the secondary $1 a$ end. If the insulation of the VT winding deteriorates, $R$ will be greatly reduced. The equivalent model is shown in Figure 4.

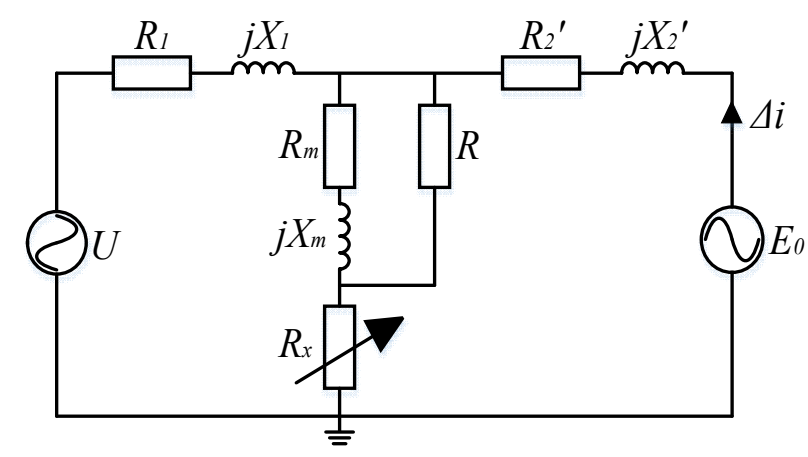

Figure 4. Equivalent model for the online detection of VT insulation. 
In Figure $4, E_{0}$ is the injection source of a small current disturbance $\Delta i, U$ is the primary-side voltage of the VT, $R_{1}$ and $j X_{1}$ are the primary winding resistance and leakage reactance of the transformer, respectively, $R_{m}$ and $j X_{m}$ are the excitation resistance and excitation reactance of the transformer, respectively, $R_{2}{ }^{\prime}$ and $j X_{2}{ }^{\prime}$ are respectively the winding resistance and leakage reactance of the secondary side of the transformer, which is reduced to the primary side, $R_{x}$ is the resistance of the harmonic elimination device, and $R$ is the insulation resistance.

In the equivalent model $Z_{1}=R_{1}+j X_{1}$, let, $Z_{2}{ }^{\prime}=R_{2}{ }^{\prime}+j X_{2}{ }^{\prime}, Z=\frac{\left(R_{m}+j X_{m}\right) R}{R_{m}+j X_{m}+R}$. Figure 4 can then be simplified to Figure 5.

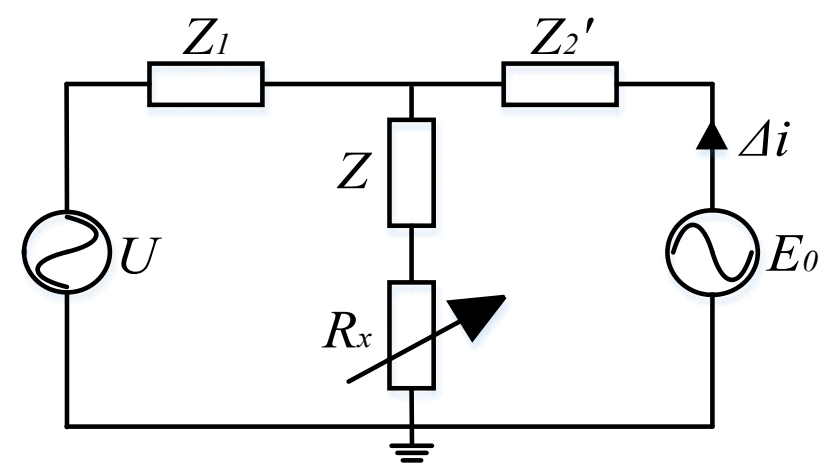

Figure 5. Simplified model for the online detection of transformer insulation.

In the simplified model, the opening voltage value, which is measured from the secondary side, is $U_{1}{ }^{\prime}$ before the shorting switch $\mathrm{KM}$ is closed and is calculated as:

$$
U_{1}{ }^{\prime}=U \frac{Z+R_{x}}{Z+R_{x}+Z_{1}}
$$

Equation (1) shows that, due to the presence of harmonic eliminator $R_{x}$, even if the insulation is completely deteriorated, that is, $Z=0, U_{1}{ }^{\prime}$ hardly changes. At this time, the three-phase secondary side voltages are $U_{1 a}{ }^{\prime}, U_{1 b}{ }^{\prime}$ and $U_{1 c}{ }^{\prime}$, and the zero-sequence voltage $3 U_{0}{ }^{\prime}=U_{1 a}{ }^{\prime}+U_{1 b}{ }^{\prime}+U_{1 c}{ }^{\prime}$.

After the shorting switch KM is closed, a small current disturbance signal $\Delta i$ is injected, and the opening voltage value measured from the secondary side is $U_{2}{ }^{\prime}$. If the current flowing into the $Z_{1}$ branch is $\Delta i_{1}$ and the current flowing into the $Z$ branch is $\Delta i_{2}$, then:

$$
\begin{gathered}
Z_{1} \Delta i_{1}+U=\Delta i_{2}\left(Z+R_{x}\right), \\
\Delta i_{1}+\Delta i_{2}=\Delta i, \\
U_{2}{ }^{\prime}=Z_{2}{ }^{\prime} \Delta i+Z_{1} \Delta i_{1}+U,
\end{gathered}
$$

Then, (2)-(4) yield:

$$
U_{2}{ }^{\prime}=Z_{2}{ }^{\prime} \Delta i+\frac{\left(Z_{1} \Delta i+U\right)\left(Z+R_{x}\right)}{Z+R_{x}+Z_{1}},
$$

After the short-circuit switch KM is broken, the small current disturbance signal $\Delta i$ will not disappear immediately, and a circulation will be formed in the VT primary circuit until the power signal is absorbed. At this time, the voltage value measured from the secondary side is $U_{3}{ }^{\prime}$. The superposition of the primary side voltage $U$ and the small current disturbance signal $\Delta i$ can be obtained as follows:

$$
U_{3}{ }^{\prime}=U \frac{Z+R_{x}}{Z+R_{x}+Z_{1}}+\Delta i\left(Z+R_{x}+Z_{1}\right),
$$


At this time, the three-phase secondary side opening voltages are $U_{3 a}{ }^{\prime}, U_{3 b}{ }^{\prime}$ and $U_{3 c}{ }^{\prime}$, and the zero-sequence voltage is:

$$
3 U_{0}{ }^{\prime}=U_{3 a}{ }^{\prime}+U_{3 b}{ }^{\prime}+U_{3 c}{ }^{\prime}=\left(U_{a}+U_{b}+U_{c}\right) \frac{Z+R_{x}}{Z+R_{x}+Z_{1}}+\Delta i\left(Z+R_{x}+Z_{1}\right) \approx \Delta i\left(Z+R_{x}+Z_{1}\right),
$$

Equation (7) shows that when the winding insulation is damaged, $Z$ (or $R$ ) decreases, and then the zero-sequence voltage disappears eventually as the vibration of the small current disturbance signal $\Delta i$ attenuates.

\section{Secondary Voltage Value of VT}

When the VT is operating normally, that is, the zero-sequence circuit is not applying a small current disturbance signal $\Delta i$, the three-phase voltage and zero-sequence voltage obtained from the secondary end of the VT are measured. The values obtained when the insulation at the end of the transformer winding is normal and in breakdown (the resistance between $\mathrm{N}$ and $1 a$ is zero) are compared in Figure 6.

When the insulation is normal, the three-phase voltage (secondary) effective values are $55.16 \mathrm{~V}$, $57.28 \mathrm{~V}$, and $57.7 \mathrm{~V}$, and the zero-sequence voltage is $1.56 \mathrm{~V}$. When the insulation is in breakdown, the three-phase voltage (secondary) effective values are $57.07 \mathrm{~V}, 56.08 \mathrm{~V}$, and $57.07 \mathrm{~V}$, and the zero-sequence voltage is $0.64 \mathrm{~V}$. The amplitude changes between the two states are not obvious.

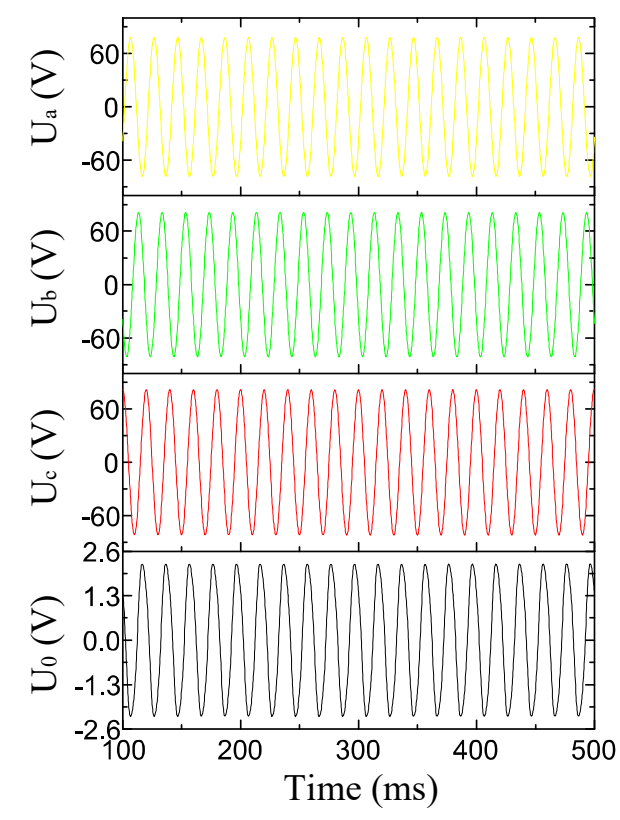

(a)

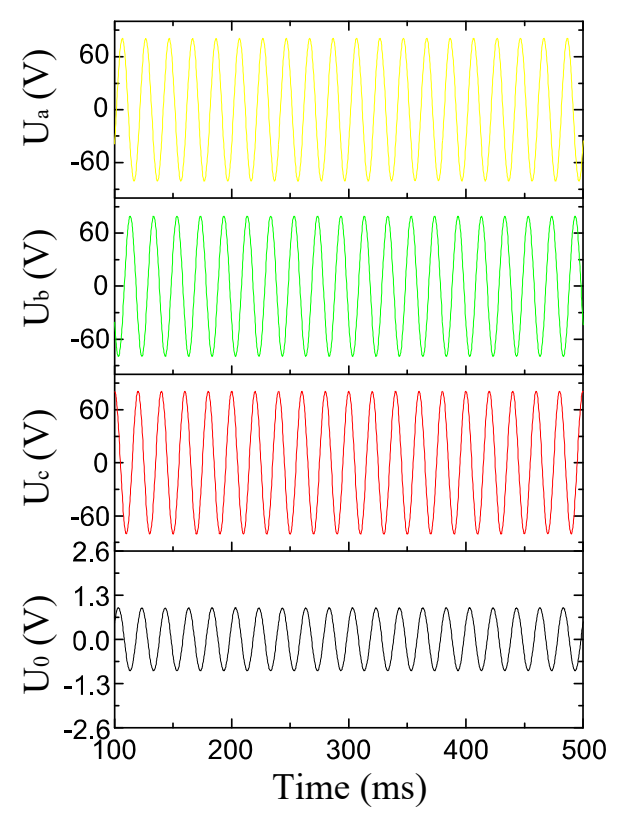

(b)

Figure 6. Simulation results for the VT secondary voltage waveform. (a) Normal insulation; (b) insulation breakdown.

Figure 7 shows the test results of the three-phase voltage and the zero-sequence voltage obtained from the secondary end of the VT when the insulation states of the VT ground N end are normal and in breakdown. When the insulation is normal, the three-phase voltage (secondary) effective values are $61.33 \mathrm{~V}, 59.57 \mathrm{~V}$, and $59.72 \mathrm{~V}$, and the zero-sequence voltage is $4.3 \mathrm{~V}$. When the insulation is in breakdown, the three-phase voltage (secondary) effective values are $61.33 \mathrm{~V}, 61.07 \mathrm{~V}$, and $58.92 \mathrm{~V}$, and the zero-sequence voltage is $1.08 \mathrm{~V}$. The amplitude changes between the two states are also not obvious. 


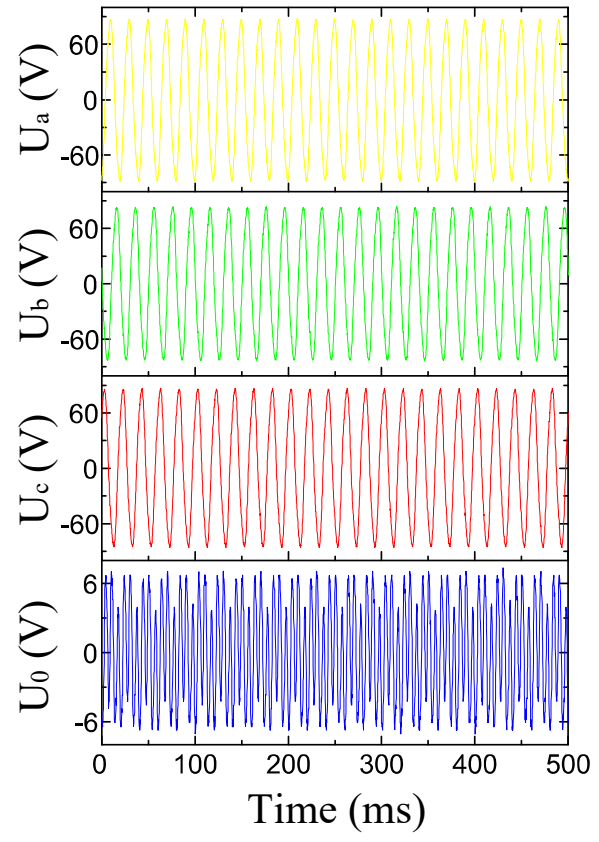

(a)

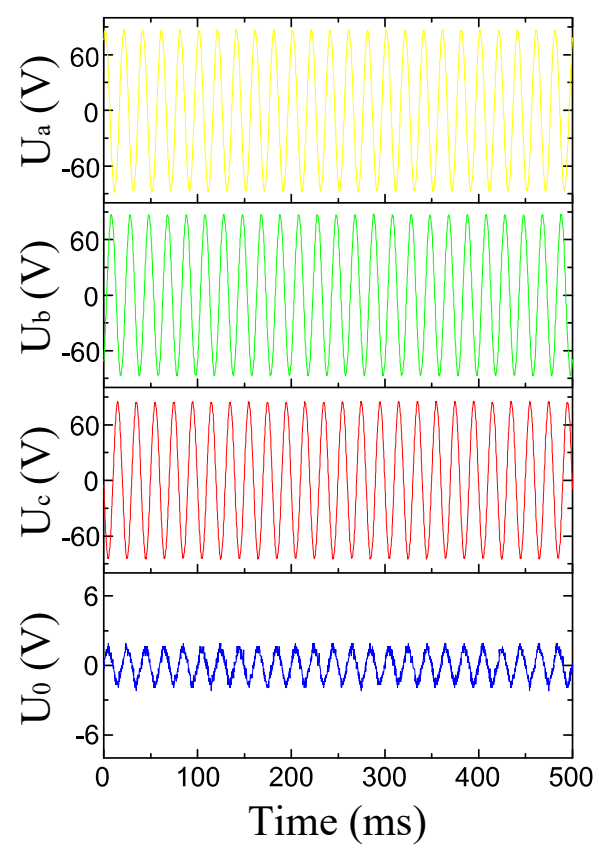

(b)

Figure 7. Test results for the VT secondary voltage waveform. (a) Normal insulation; (b) insulation in breakdown.

The results of the above simulation and test show that the VT operates normally because of the existence of the harmonic elimination device whether the winding of the transformer is insulated or not. That is, the amplitude and waveform of the three-phase and zero-sequence voltages do not change obviously.

\section{Test Simulation Analysis of VT Insulation}

A simulation evaluation was carried out to evaluate the proposed method. The simulation model is shown in Figure 8.

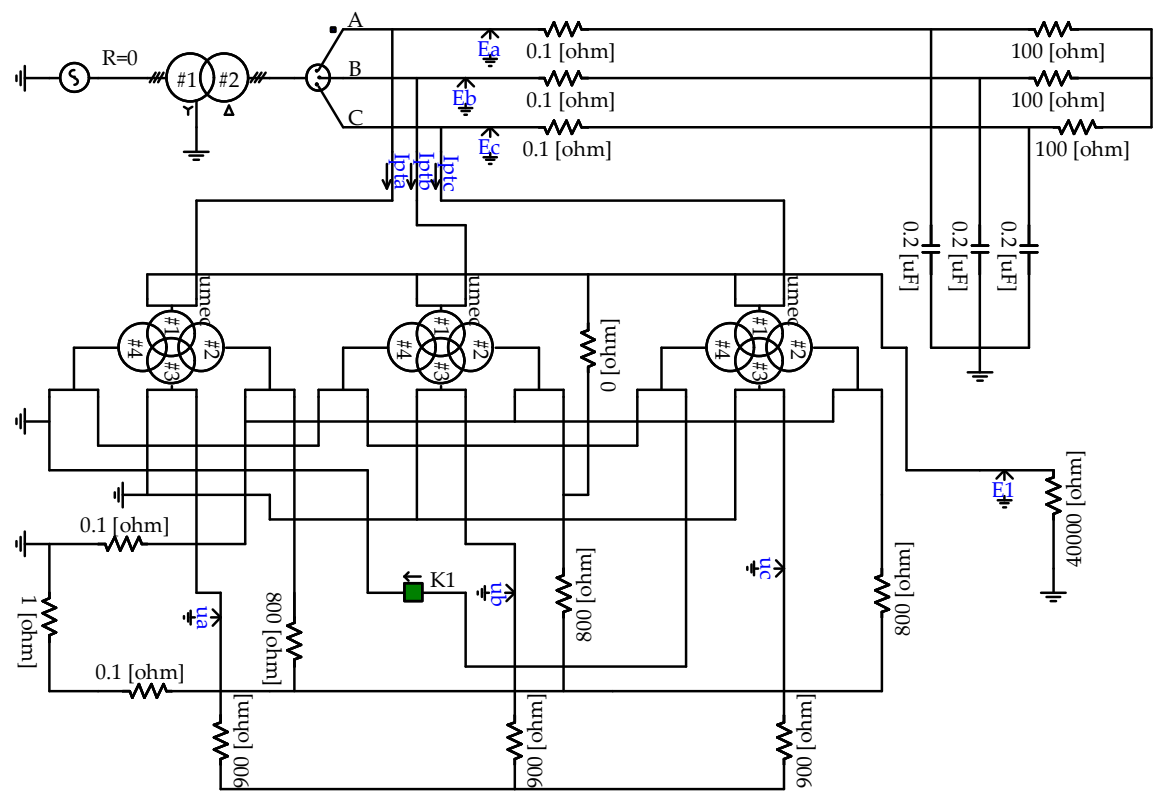

Figure 8. PSCAD simulation model. 
Different values of insulation resistance $R$ were connected to the $\mathrm{N}$ terminal of the VT and the secondary winding $1 a$ end of the B phase VT. The switch (K1) is shorted at the opening triangle of the VT. After being connected for $80 \mathrm{~ms}$, the switch is opened and the zero-sequence voltage change before and after the switch has been shorted is analyzed. The capacitance in Figure 8 is the capacitance of the line to ground, and the capacitance value is $0.2 \mathrm{uF}$. Since the ferromagnetic resonance of the distribution network occurs in the zero-sequence loop, the interphase capacitance, the bus capacitor bank and the active and reactive load in the power grid do not contribute to the resonance and can be ignored.

\subsection{Simulation Results and Analysis}

Figure 9 shows the voltage waveforms when the insulation resistance $R$ is $0 \Omega, 200 \Omega$, and $5 \mathrm{k} \Omega$.

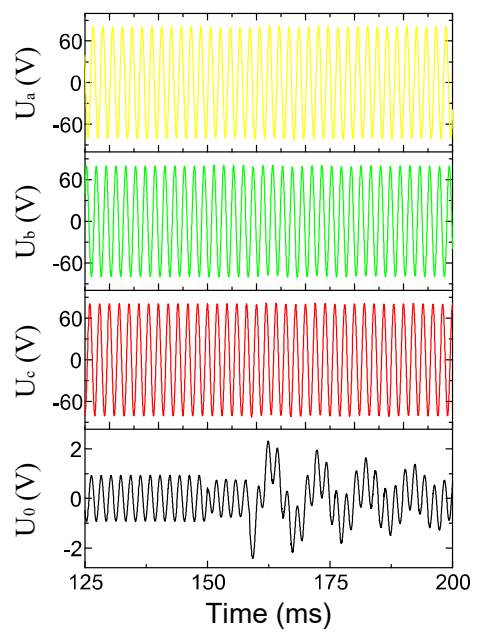

(a)

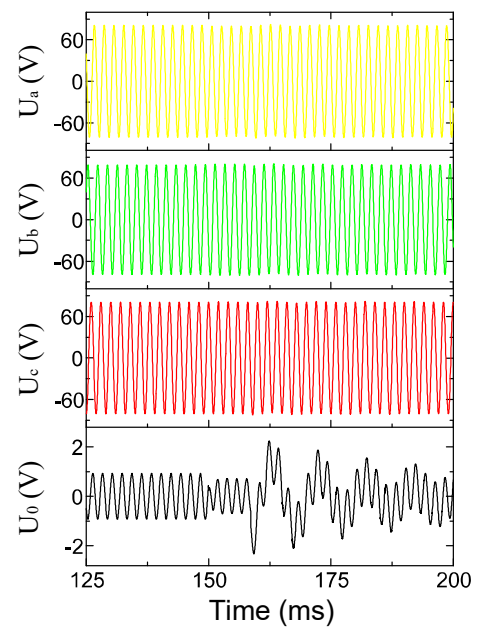

(b)

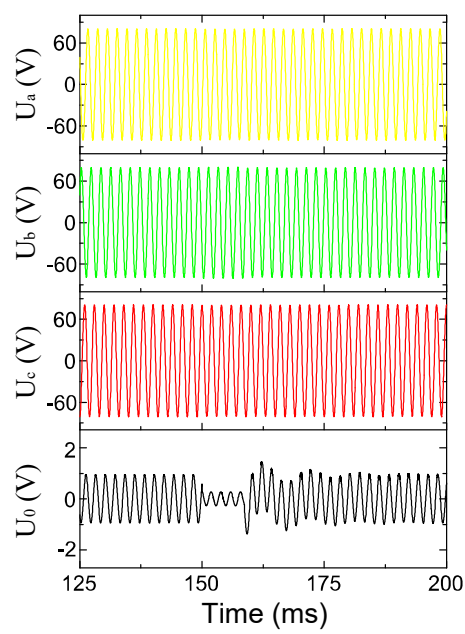

(c)

Figure 9. Voltage waveforms. (a) $R=0 \Omega$; (b) $R=200 \Omega$; (c) $R=5 \mathrm{k} \Omega$.

Figure 10 shows the value of $U_{0}$ within one second after $\mathrm{K} 1$ has been closed and open. The left column is a Fourier analysis of the data and the right column shows the signal after low-pass filtering with a cutoff frequency of $30 \mathrm{~Hz}$.
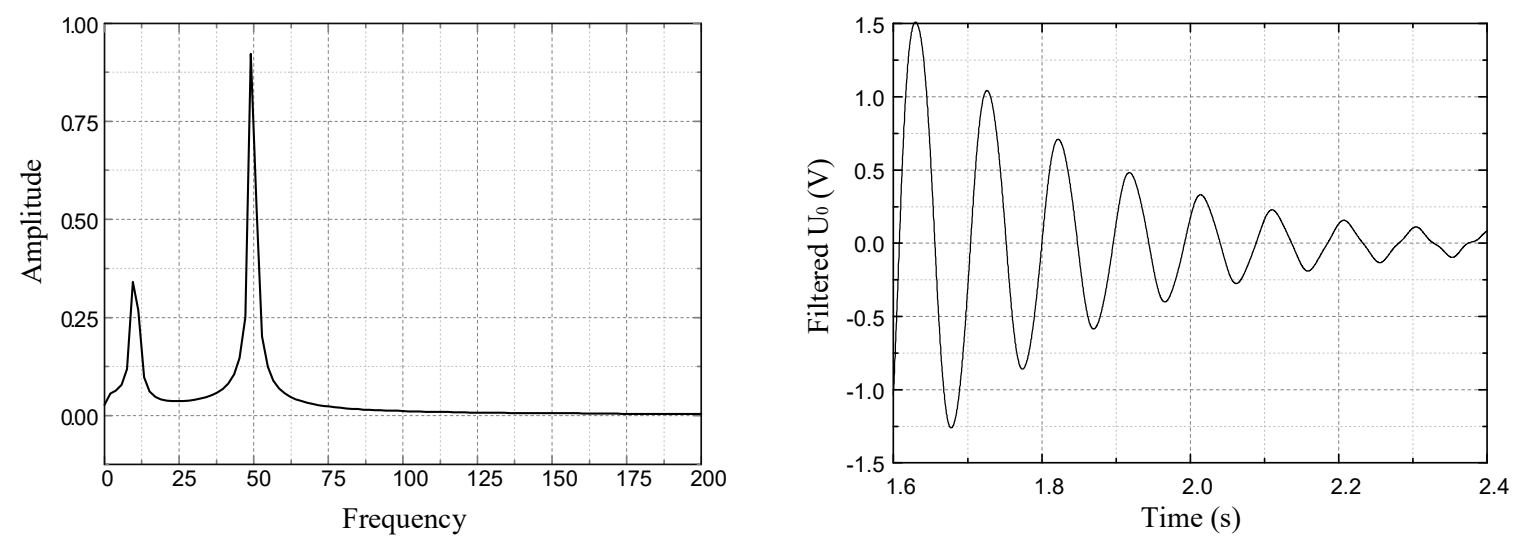

(a)

Figure 10. Cont. 

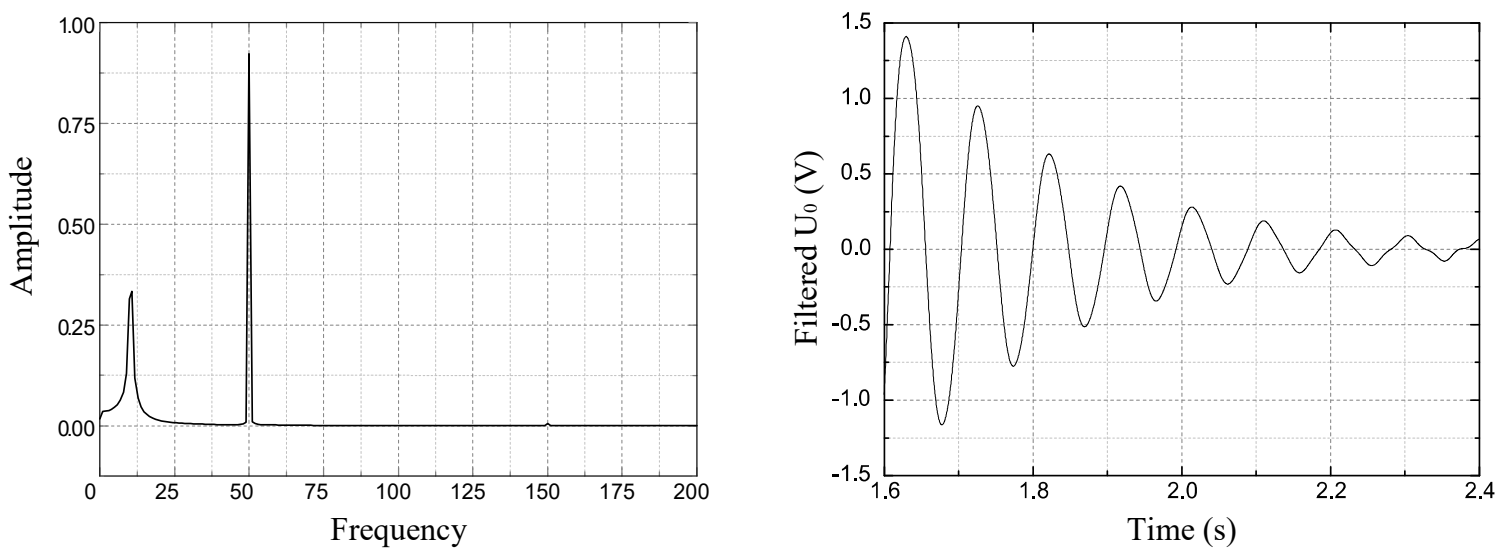

(b)
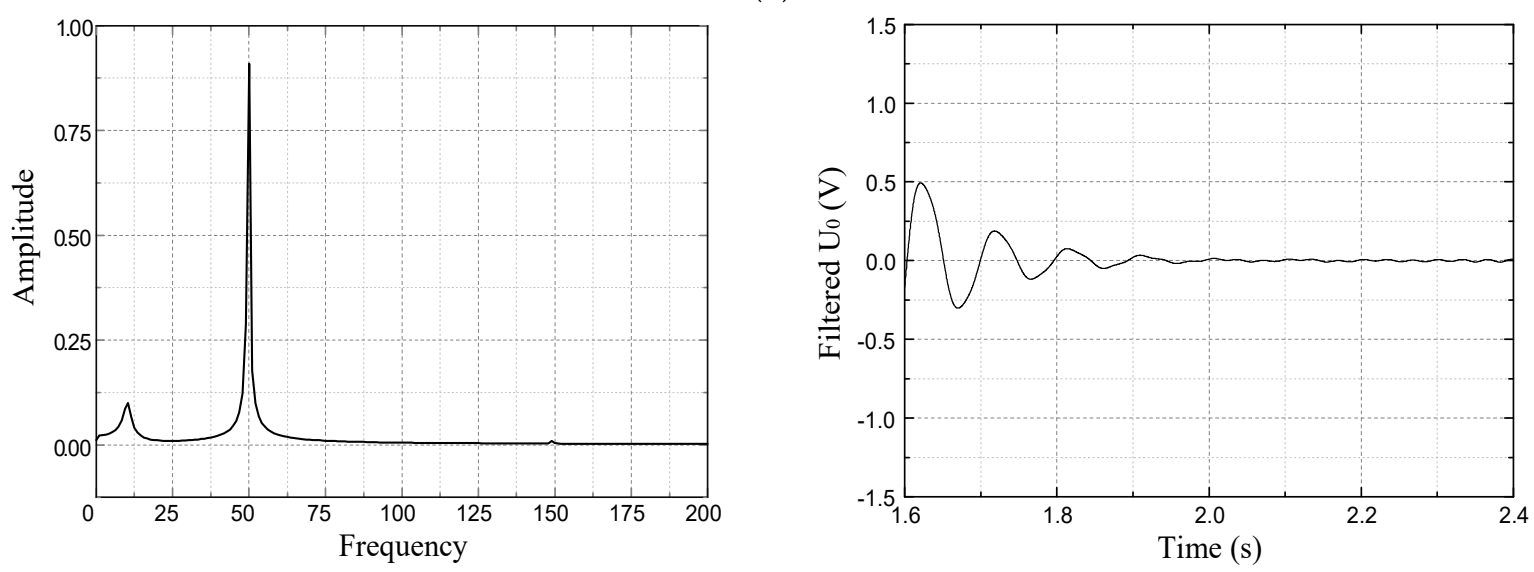

(c)

Figure 10. Zero-sequence voltage analysis results. (a) $R=0 \Omega$; (b) $R=200 \Omega$; (c) $R=5 \mathrm{k} \Omega$.

According to the filtered waveforms shown in Figure 10, when $R$ is $0 \Omega, 200 \Omega$, and $5 \mathrm{k} \Omega$ and $\mathrm{K} 1$ is closed and opened, $U_{0}$ has a low frequency oscillation of about $10 \mathrm{~Hz}$. The maximum amplitudes are $1.5 \mathrm{~V}, 1.4 \mathrm{~V}$, and $0.5 \mathrm{~V}$, respectively. The oscillation duration is approximately 670, 620 and $320 \mathrm{ms,}$ respectively. The duration is defined as the time from the peak of the first oscillation to the peak that has a maximum amplitude of $1 / 10$ or less relative to the first oscillation. Figure 11 shows the same data for $U_{0}$ when $R=\infty$, that is, the $\mathrm{N}$ terminal insulation of the VT is normal.
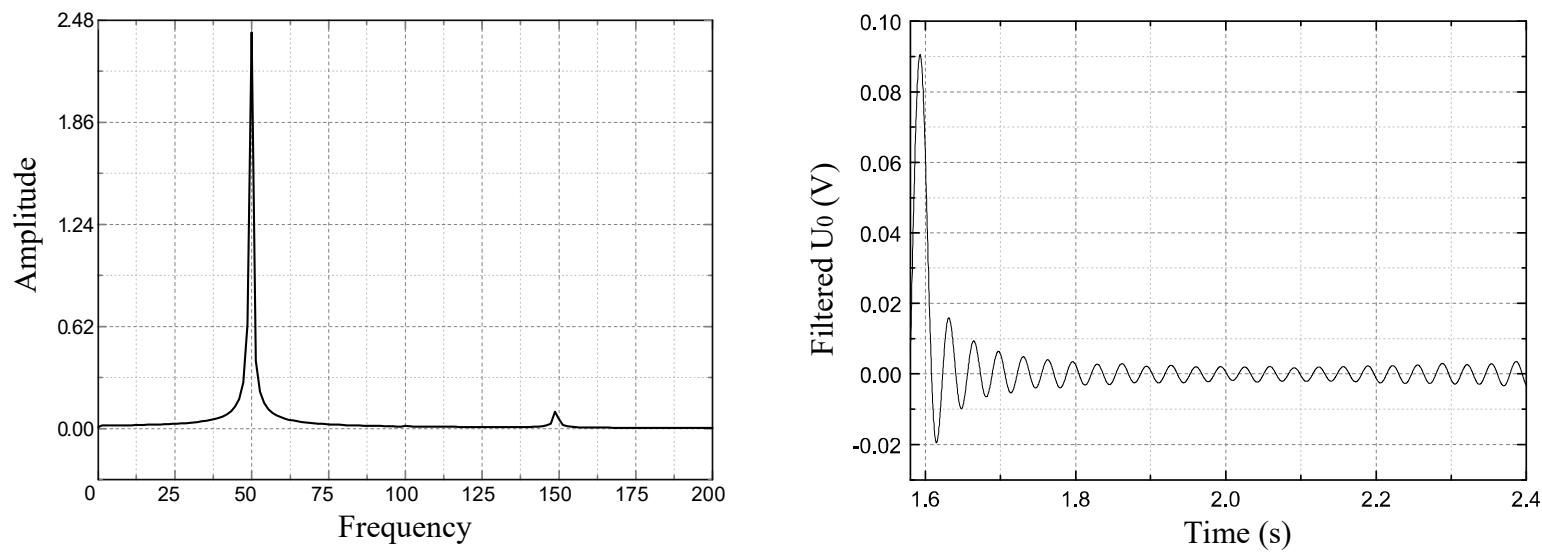

Figure 11. Zero-sequence voltage analysis result when $R=\infty$. 
According to the filtered waveform in Figure 11, when $R=\infty$ and $\mathrm{K} 1$ is operated, a low frequency oscillation of about $30 \mathrm{~Hz}$ occurs on $U_{0}$. The maximum amplitude is $0.09 \mathrm{~V}$, and the oscillation duration is about $80 \mathrm{~ms}$.

\subsection{Analysis and Discussion}

Figure 12 shows the simulation results for the maximum low-frequency oscillation amplitude and duration of $U_{0}$ as the insulation resistance $R$ changes after $\mathrm{K} 1$ is closed and opened.

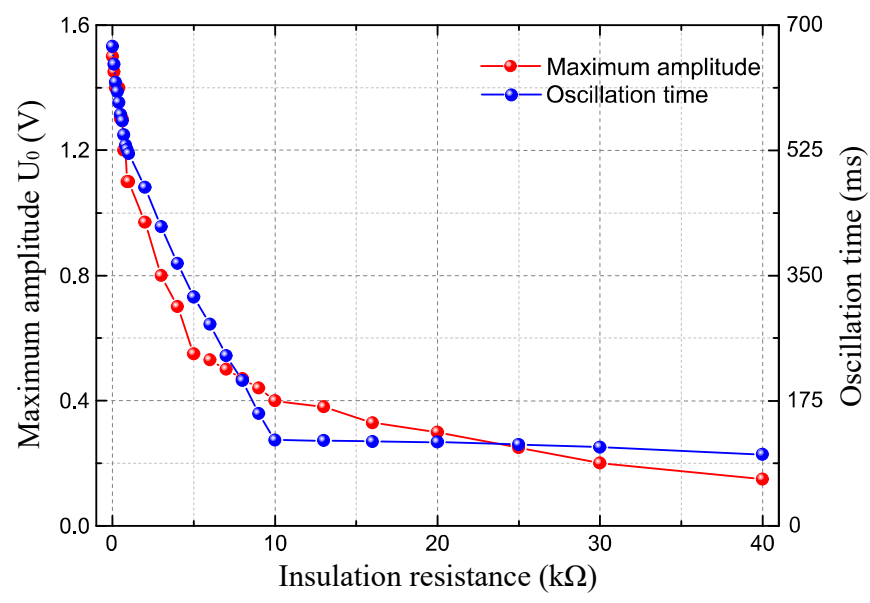

Figure 12. Zero-sequence voltage change.

It can be seen from the change in zero-sequence voltage that when the insulation resistance value $R$ is $0-40 \mathrm{k} \Omega$, a low-frequency oscillation with a duration of about several hundred milliseconds and an oscillation frequency of about $10 \mathrm{~Hz}$ occurs. Both the voltage amplitude and the oscillation time are inversely proportional to the insulation resistance and proportional to the degree of insulation degradation of the VT winding. When the insulation resistance value $R$ ranges from $10 \mathrm{k} \Omega$ to insulation breakdown, the variation of the characteristic parameters of the zero-sequence voltage low-frequency oscillation is obvious. When resistance $R$ decreases from $40 \mathrm{k} \Omega$ to $10 \mathrm{k} \Omega$, the variation of the low-frequency oscillation parameters is relatively flat. When the insulation resistance exceeds $40 \mathrm{k} \Omega$, both the voltage amplitude and oscillation time are not much different from those of normal insulation. When the VT insulation is normal, the low frequency oscillation frequency appearing on the zero-sequence voltage is about $30 \mathrm{~Hz}$, and the oscillation amplitude is below $0.1 \mathrm{~V}$. Therefore, in order to avoid deterioration of VT insulation and cause a larger grid accident, we can evaluate the insulation of the VT winding by this method, that is, the different characteristics of the VT zero-sequence voltage low-frequency oscillation.

\section{VT Insulation Experiment}

\subsection{Experiment Method}

The simulation results were verified by experiments. The basic diagram of the test is shown in Figure 13. A voltage transformer group was connected to a $10 \mathrm{kV}$ bus and a harmonic elimination device $R_{x}$ was installed. A fixed resistor was connected to the $\mathrm{N}$-terminal of the primary winding and the 1a end of the secondary winding at the A-phase voltage transformer to simulate damage to the N-terminal insulation of the voltage transformer. A controllable switch KM was connected to the triangular end of the VT opening. In addition, the KM was remotely controlled so that it closed for about $50 \mathrm{~ms}$. Three-phase voltage waveforms were measured at the $2 a$ and $2 n$ ends of the VT secondary winding. The three-phase voltage was synthesized into a zero-sequence voltage, and the change in this voltage were observed before the KM was closed and after the KM was opened. 


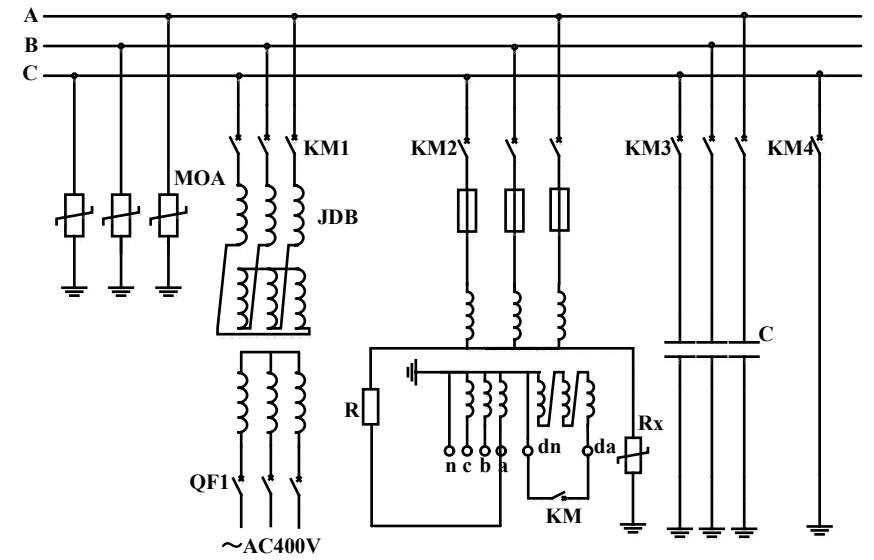

Figure 13. Test schematic.

The field test setup is shown in Figure 14.
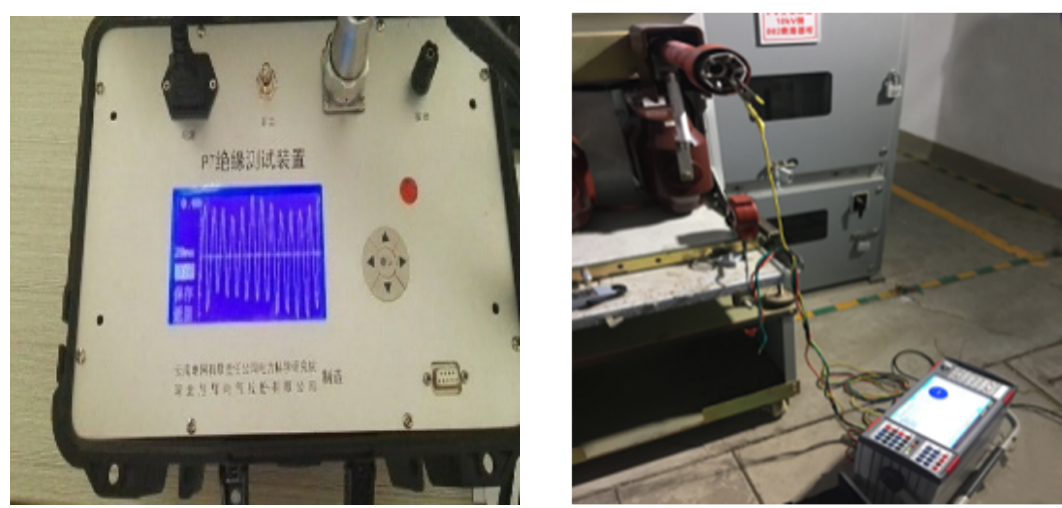

Figure 14. Online detection device test.

\subsection{Test Results and Analysis}

Figure 15 shows the voltage waveform obtained when the insulation resistance $R=\infty$, that is, when the insulation of the VT winding is normal.

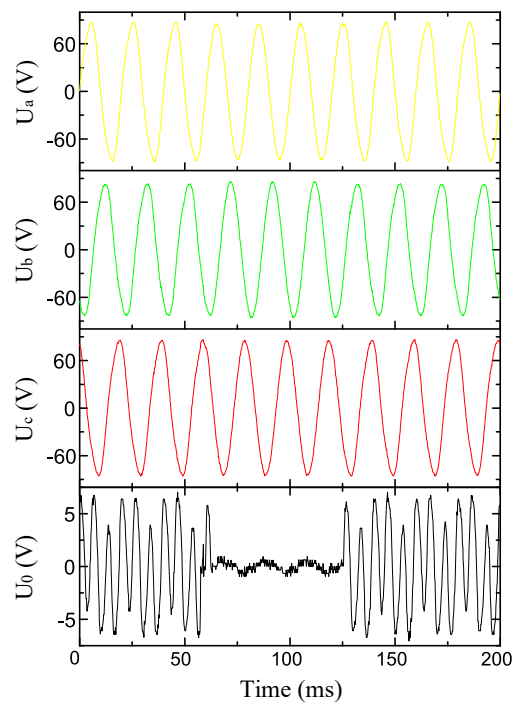

Figure 15. Voltage waveform when the insulation is normal. 
In the waveform diagram, the period during which voltage $U_{0}$ is substantially lowered is when KM closes. The spectra of the experimental data for $1 \mathrm{~s}$ before and after KM operation is shown in Figure 16.
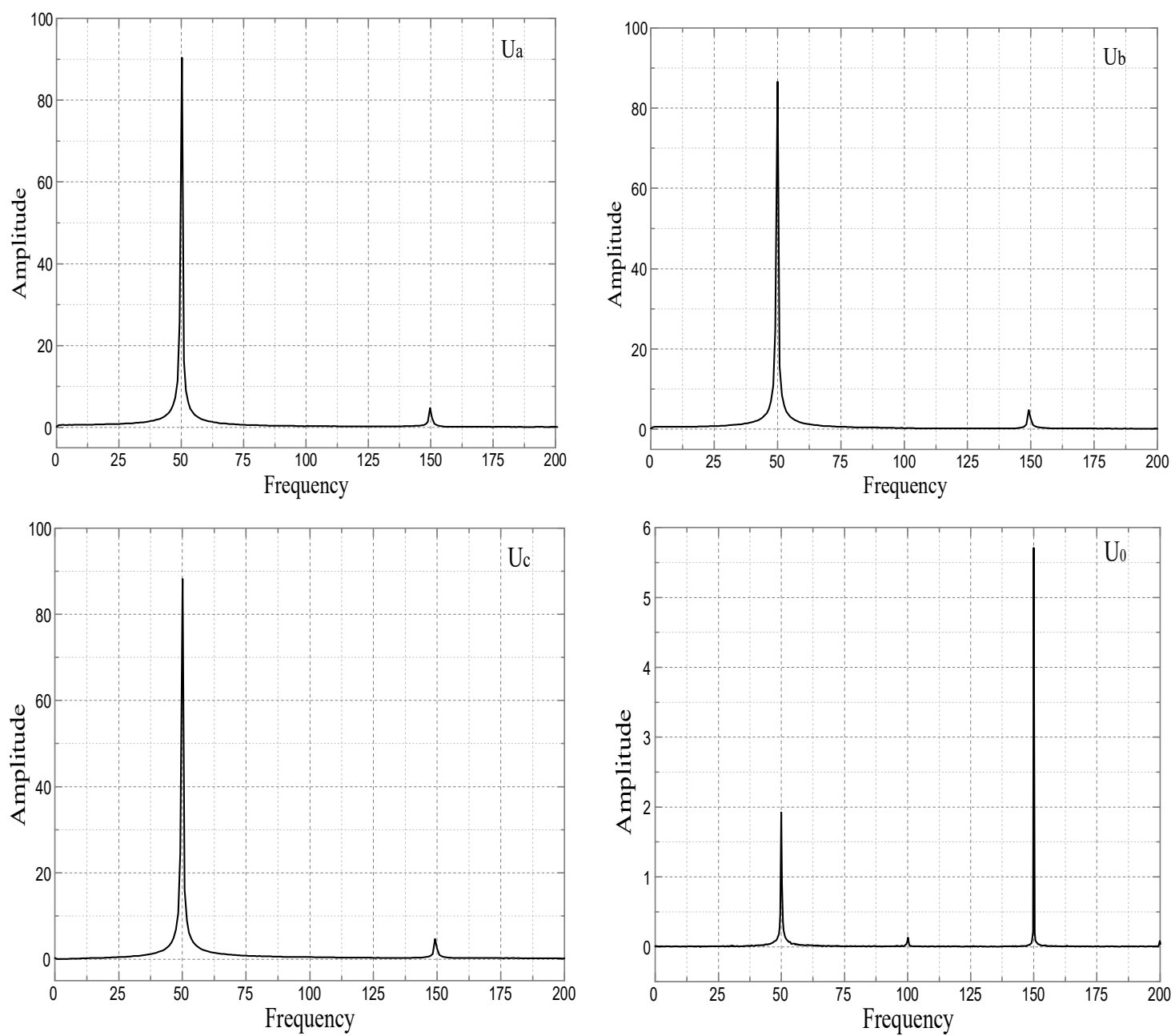

(a)
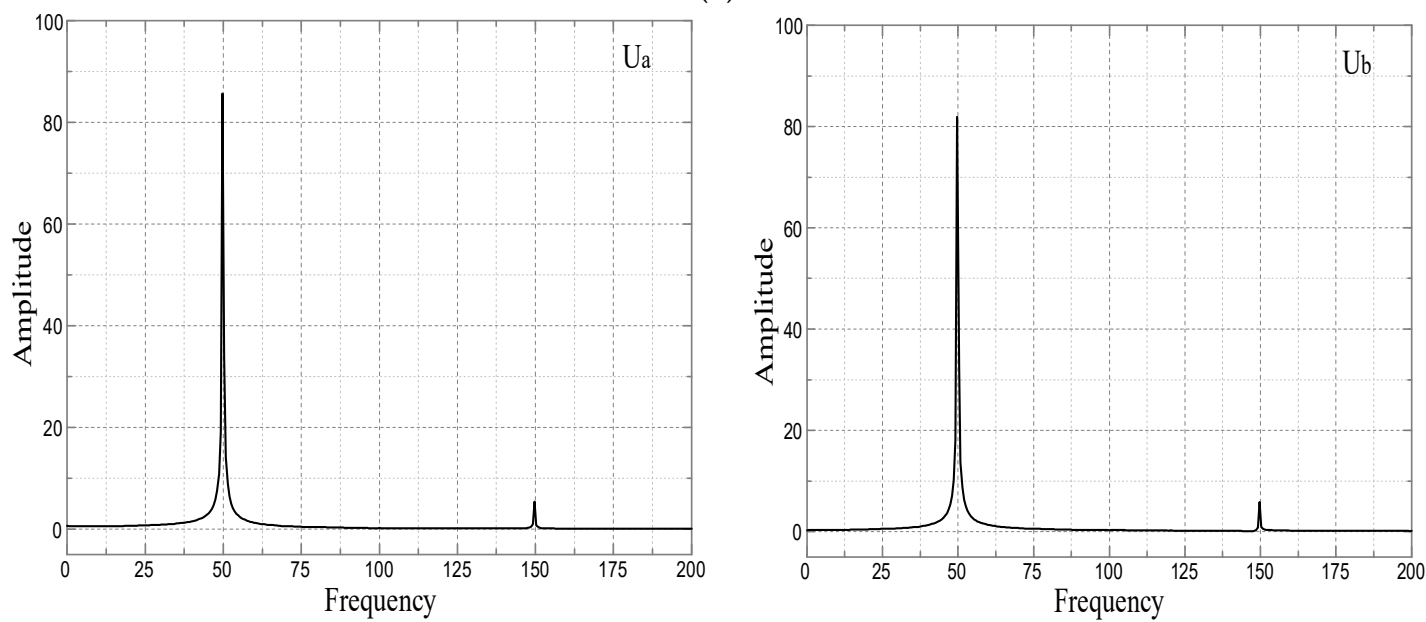

Figure 16. Cont. 

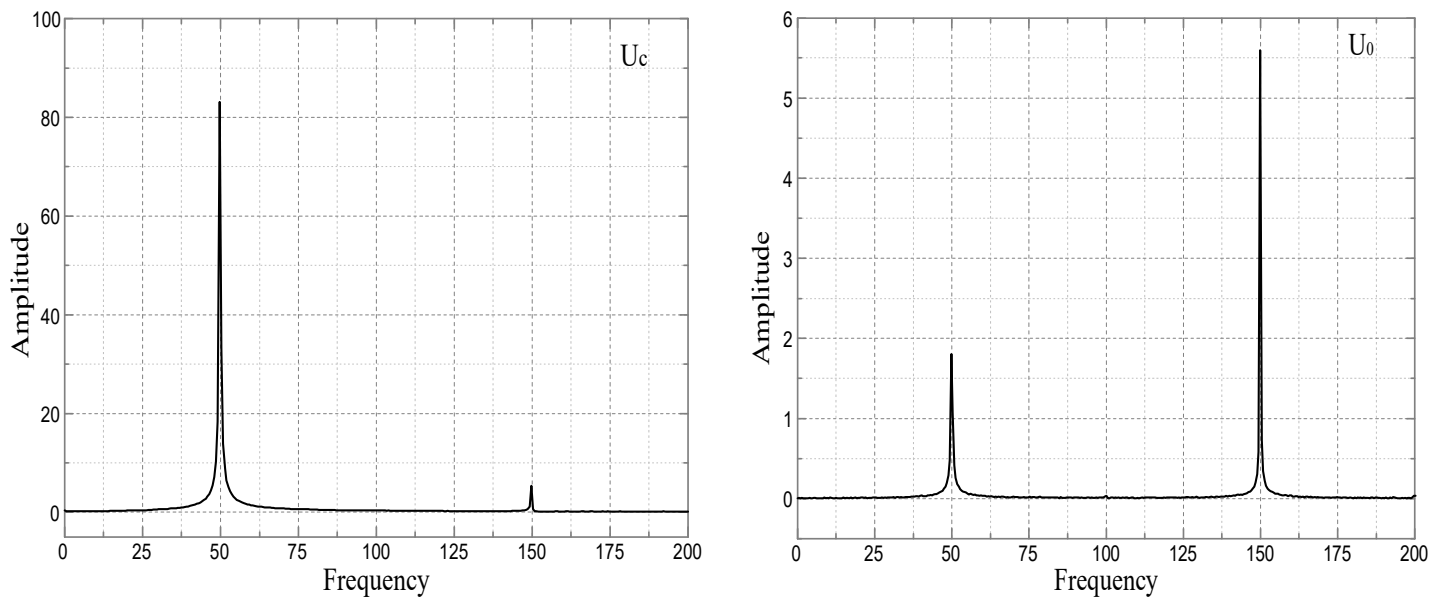

(b)

Figure 16. Amplitude of the frequency spectra of the phase voltages. (a) Before KM is closed. (b) after $\mathrm{KM}$ is opened.

The zero-sequence voltage measured after the KM was opened was passed through a low-pass filter with a cutoff frequency of $30 \mathrm{~Hz}$, and the results are shown in Figure 17. It shows that there is no significant difference in the voltage before $\mathrm{KM}$ is closed and after it is opened.

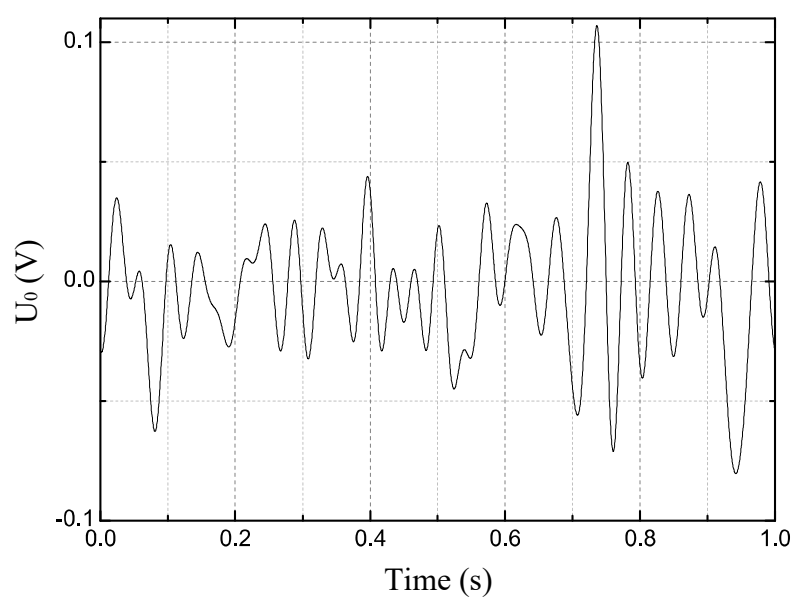

Figure 17. Zero-sequence voltage low-pass filtered waveform.

To simulate deterioration of the insulation, a fixed resistor was used to connect the $\mathrm{N}$ terminal and 1a terminal of the A phase VT. KM was opened after being closed for $50 \mathrm{~ms}$. Figure 18 shows the voltage waveform for resistance $R=5 \mathrm{k} \Omega$. As Figure 18 shows, after $K M$ is broken, the $U_{0}$ waveform obviously oscillates. The frequency amplitudes of the experimental data $1 \mathrm{~s}$ before and after KM operation are shown in Figure 19. 


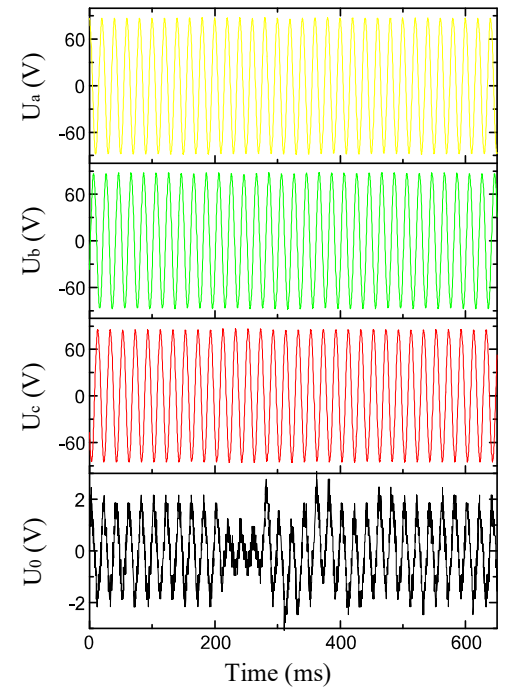

Figure 18. Voltage waveform before and after KM action.
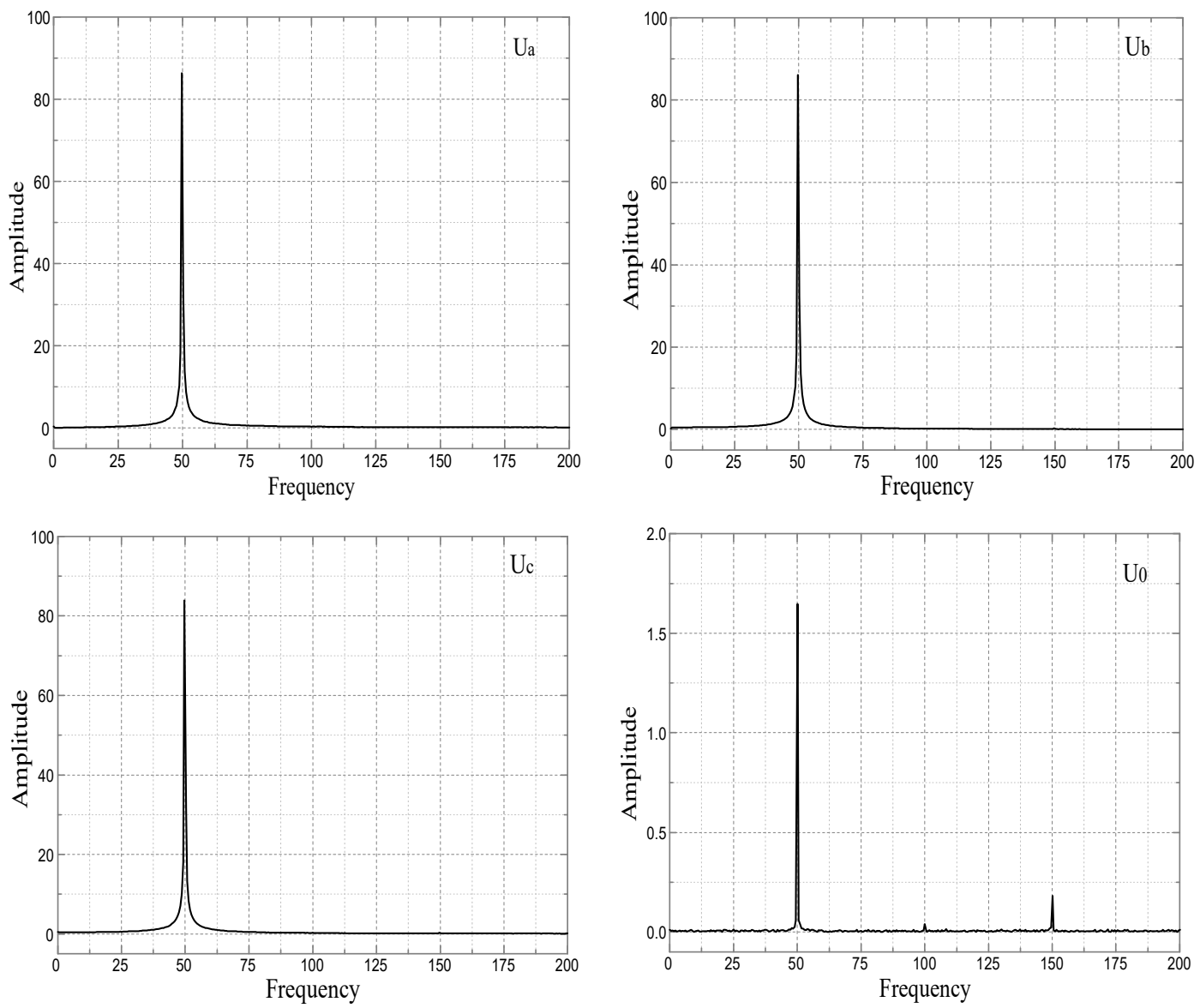

(a)

Figure 19. Cont. 

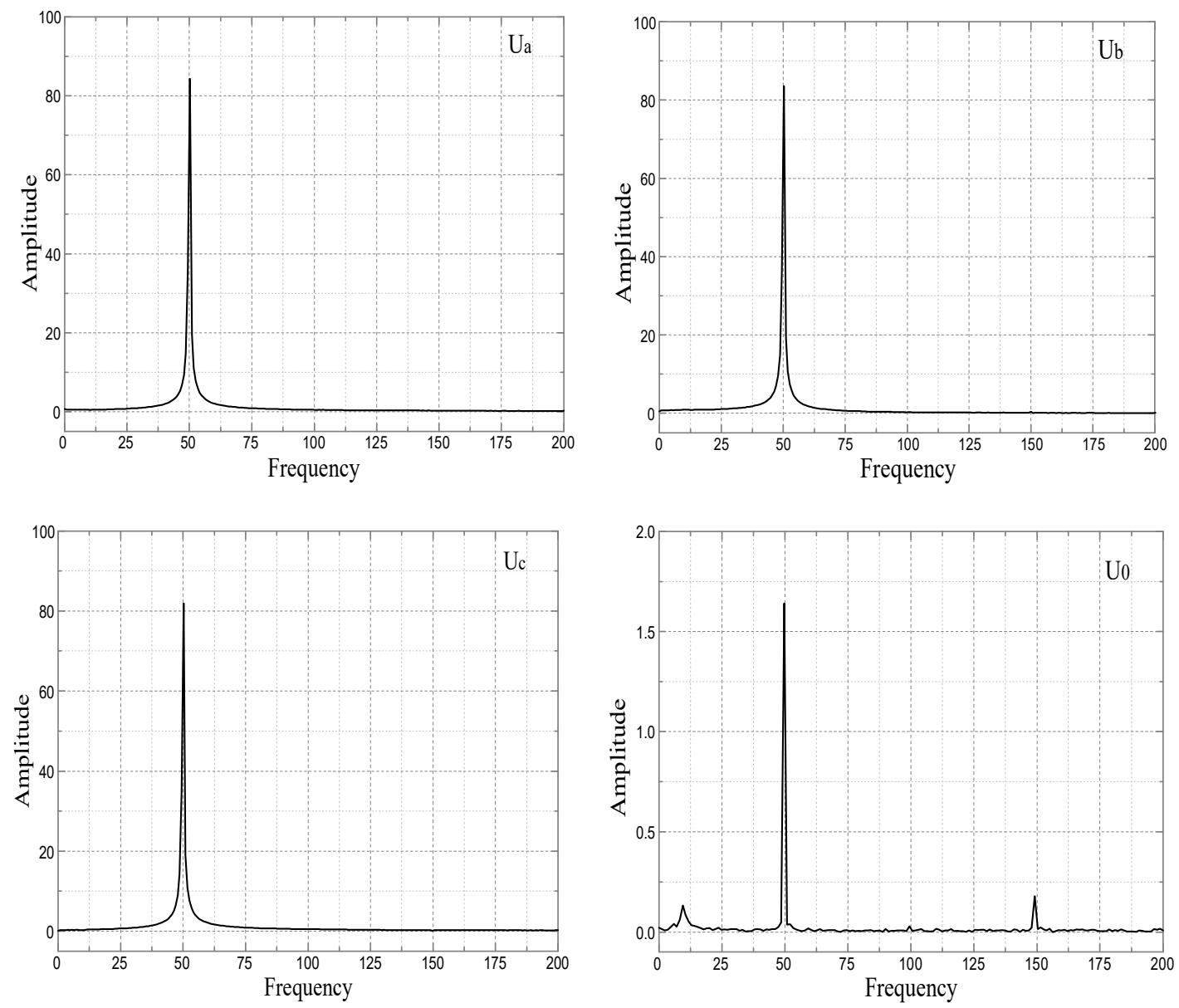

(b)

Figure 19. Amplitude of the frequency spectra of phase voltages. (a) Before KM is closed; (b) after KM is opened.

Comparing Figures 16 and $19(R=\infty$ and $5 \mathrm{k} \Omega$, respectively) there is no significant difference in the fundamental amplitude of the three-phase and zero-sequence voltage before KM is closed. In addition, the third harmonic component is substantially reduced. When $R=\infty$, the third harmonic amplitudes of the three-phase voltage are $4.9 \mathrm{~V}, 5.2 \mathrm{~V}$, and $5.0 \mathrm{~V}$, and that of the zero-sequence voltage is $5.7 \mathrm{~V}$. When $R=5 \mathrm{k} \Omega$, the voltages of the third harmonic amplitude are $0.01 \mathrm{~V}, 0.3 \mathrm{~V}$, and $0.17 \mathrm{~V}$ (three-phase voltage) and $0.18 \mathrm{~V}$ (zero-sequence voltage). After the KM has been broken, there is no significant difference in the fundamental amplitudes of the three-phase and zero-sequence voltages, and the third harmonic component is substantially reduced. When $R=\infty$, the third harmonic amplitudes are $5 \mathrm{~V}$, $5.2 \mathrm{~V}$, and $5.0 \mathrm{~V}$ (three-phase voltage), and $5.7 \mathrm{~V}$ (zero-sequence voltage). When $R=5 \mathrm{k} \Omega$, the third harmonic amplitudes are $0.03 \mathrm{~V}, 0.28 \mathrm{~V}$, and $0.17 \mathrm{~V}$ (three-phase voltage), and $0.19 \mathrm{~V}$ (zero-sequence voltage). Comparing the voltage spectra before and after KM operation when $R=5 \mathrm{k} \Omega$, it can be seen that the fundamental frequency amplitude and third harmonic component of the three-phase voltage do not change substantially. The low-pass-filtered zero-sequence voltage after the KM is opened is shown in Figure 20. 


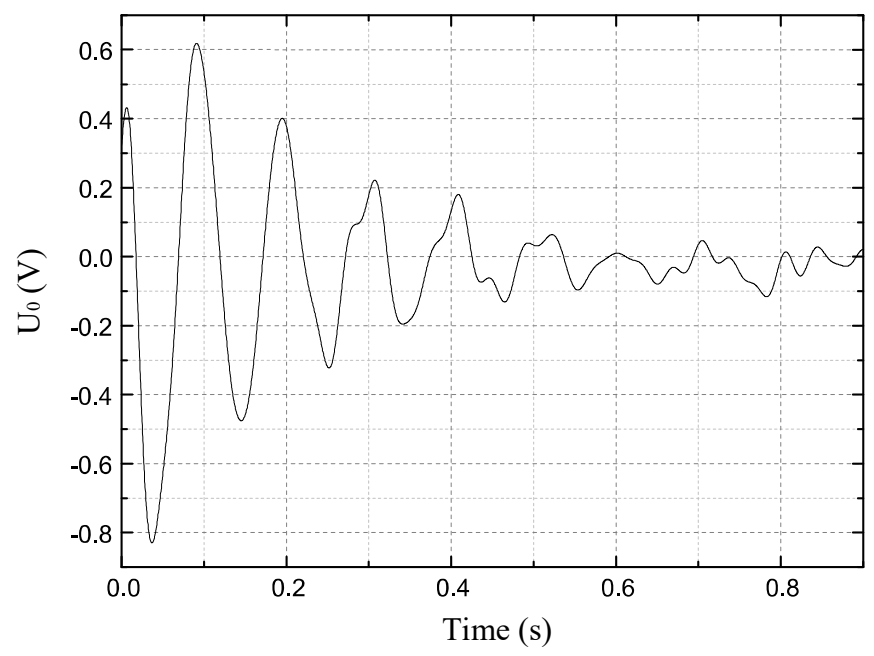

Figure 20. Zero-sequence voltage filter waveform.

When $R=5 \mathrm{k} \Omega$, a low-frequency oscillation with a frequency of about $10 \mathrm{~Hz}$ and a maximum amplitude of $0.82 \mathrm{~V}$ occurs on the zero-sequence voltage, and the oscillation duration is about $520 \mathrm{~ms}$.

\subsection{Analysis and Discussion}

Using KM to short-circuit the VT opening triangle and then breaking it causes an obvious low-frequency oscillation to appear on the zero-sequence voltage. As insulation resistance $R$ changes, different maximum amplitudes and durations of $U_{0}$ low frequency oscillations are obtained in the filtered zero-sequence voltage. This trend is shown in Figure 21.

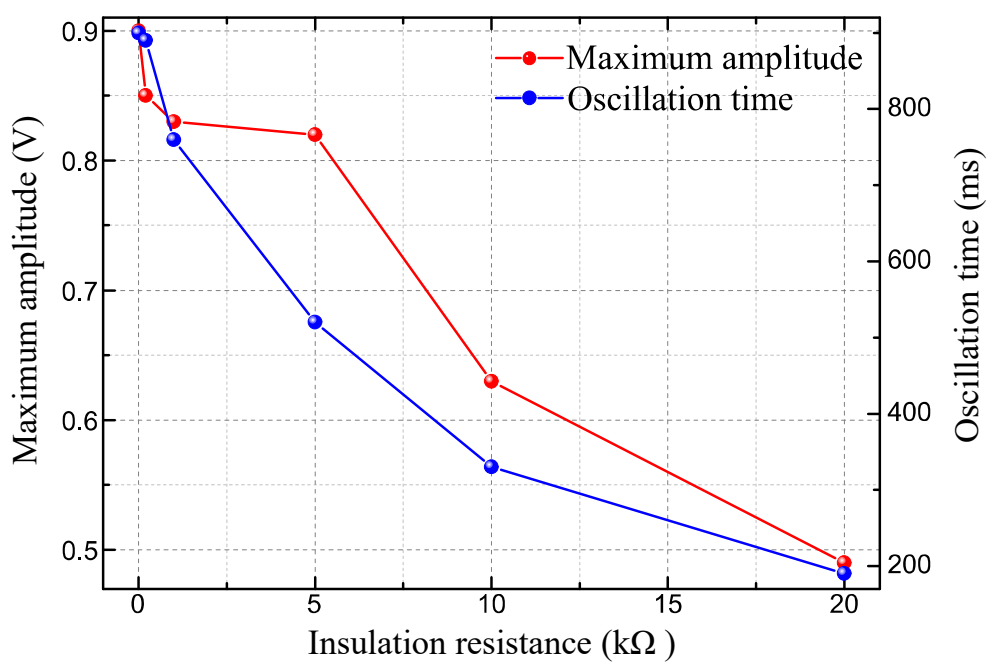

Figure 21. Zero-sequence voltage change with respect to insulation resistance.

When the insulation resistance between the $\mathrm{N}$ terminal and the 1a terminal of the VT is lowered to $5 \mathrm{k} \Omega$ or less, the third harmonic component of each phase voltage is significantly reduced compared to the normal insulation condition. When the insulation resistance between the $\mathrm{N}$ terminal and the $1 \mathrm{a}$ terminal of the VT is lowered to $5 \mathrm{k} \Omega$ or less, the VT opening triangle is short-circuited and released, and the third harmonic component of each phase voltage does not change significantly before closing and after disconnection.

Figure 21 shows that the relationship between the insulation resistance of the VT winding and the low-frequency oscillation of the zero-sequence voltage obtained by the test is basically the same as that obtained by the simulation. More severe insulation damage of the VT winding causes the insulation 
resistance to decrease. When the short-circuit switch on VT open triangle is broken, the amplitude of the low frequency oscillation on the zero-sequence voltage is larger and its duration is longer.

In the test, when damage to the insulation of the VT ground N-terminal was simulated, the third harmonic component in each of the three-phase and zero-sequence voltages obtained from the secondary end of VT was substantially reduced. However, the simulation did not model this trend because the amplitude of the third harmonic in the actual system depends not only on the zero-sequence loop of the VT, but also on the load characteristics of the system. It is not reasonable to evaluate the damage of the N-terminal insulation of the VT ground using the amplitude of the third harmonic of each three-phase and zero-sequence voltage. In contrast, the low-frequency oscillation of the zero-sequence voltage has distinct characteristics: the maximum amplitude and duration are proportional to the degree of insulation damage of the VT winding and hence can be used as a criterion for evaluating damage to the insulation of the VT winding.

\section{Conclusions}

In the field test, when the VT insulation is damaged, the third harmonic content of each phase voltage and zero sequence voltage obtained from the VT secondary end is significantly reduced, but the simulation test cannot get this trend. The results of the simulation and field tests in this study reveal that the third harmonics of the three-phase and zero sequence voltages are not suitable for evaluating damage to the insulation of a VT winding. In the simulation, when insulation resistance value $R$ of the VT winding is in the range of $0-40 \mathrm{k} \Omega$, a small current disturbance is applied to the zero-sequence loop of voltage transformer, and a low-frequency oscillation of about $10 \mathrm{~Hz}$ can be detected on the zero-sequence voltage. The low-frequency oscillations of the zero-sequence voltage in normal and degraded VT windings exhibit distinct characteristics, and we can evaluate the insulation of the VT winding by this method. Specifically, the low-frequency oscillation amplitude and duration of the zero-sequence voltage are proportional to the degree of damage to the VT winding insulation, and they can hence be used as criteria for assessing VT winding insulation damage.

Author Contributions: Conceptualization, H.L., K.W. and Q.Y.; Methodology, H.L., K.W. and Q.Y.; Validation, H.L. and L.Y.; Formal Analysis, H.L., K.W. and Q.Y.; Investigation, H.L., L.Y. and J.H.; Data Curation, H.L.; Writing-Original Draft Preparation, L.Y.; Writing-Review \& Editing, Q.Y.; Funding Acquisition, K.W.

Funding: This research was funded by Yunnan electric power corporation of China (YNKJXM20170214; YNKJ00000045).

Conflicts of Interest: The authors declare no conflict of interest.

\section{References}

1. Horak, J. A review of ferroresonance. In Proceedings of the 57th Annual Conference for Protective Relay Engineers, College Station, TX, USA, 1 April 2004.

2. Nattapan, T.; Boonyang, P.; Hideaki, O. Analysis of Ferroresonance Phenomenon in $22 \mathrm{kV}$ Distribution System with a Photovoltaic Source by PSCAD/EMTDC. Energies 2018, 11, 1742.

3. He, Z.; Li, X.; Qin, J.; Huang, H. Study on Ferroresonance Over-Voltage Based on Harmonic Elimination Device. In Proceedings of the 2018 International Conference on Virtual Reality and Intelligent Systems, Changsha, China, 10-11 August 2018; pp. 460-465.

4. Cao, L.-F.; Peng, J.; Zhou, L.-X.; He, T.-F.; Huang, Z.-D.; Zhong, X.-Q. Distribution Network Ferroresonance Elimination Device Based on IGBT. J. Electric. Power 2014, 29, 32-35.

5. Yang, Q.; Zheng, Z.; Sima, W.-X.; Chen, L.; Yuan, T. Effects of MOA on chaotic ferroresonance overvoltage. High Volt. Eng. 2011, 37, 40-49.

6. Yang, M.; Yang, Q.; Sima, W.-X.; Yuan, T.; Chen, L.-J.; Huang, Y.-L. Reconstruction and Identification and Control Method of Ferroresonance Overvoltage Based on Voltage Time Series. Int. J. Mod. Phys. B 2013, 27, 45-56. [CrossRef] 
7. Walling, R.; Barker, K.; Compton, T.; Zimmerman, L. Ferroresonant overvoltages in grounded wye-wye padmount transformers with low-loss silicon steel cores. IEEE Trans. Power Deliv. 1993, 8, 1647-1660. [CrossRef]

8. Dai, Y.; Sima, W.-X.; Sun, C.; Zheng, Z.; Jiang, C. Chaos controlling in ferroresonance overvoltage with T-S fuzzy method. High Volt. Eng. 2010, 36, 878-883.

9. Li, Y.; Shi, W.; Qin, R.; Yang, J. A systematical method for suppressing ferroresonance at neutral-grounded substations. IEEE Trans. Power Deliv. 2003, 18, 1009-1014. [CrossRef]

10. Radmanesh, H.; Gharehpetian, G. Ferroresonance suppression in power transformers using chaos theory. Int. J. Electr. Power Energy Syst. 2013, 45, 1-9. [CrossRef]

11. Huang, Y.; Sima, W.-X.; Yang, Q.; Yuan, T.; Yang, M. Features extraction and validation from measured overvoltage signals of power system. High Volt. Eng. 2013, 39, 60-66.

12. Chen, L.; Yang, Q.; Wang, J.; Sima, W.-X.; Yuan, T. Classification of Fundamental Ferroresonance, Single Phase-to-Ground and Wire Breakage Over-Voltages in Isolated Neutral Networks. Energies 2011, 4, 1301-1320. [CrossRef]

13. Emin, Z.; Al Zahawi, B.; Uğur, M.; Tong, Y.K. Quantification of the chaotic behavior of ferroresonant voltage transformer circuits. IEEE Trans. Circuits Syst. I 2001, 48, 757-760. [CrossRef]

14. Mozaffari, S.; Sameti, M.; Soudack, A. Effect of initial conditions on chaotic ferroresonance in power transformers. IEE Proc. Gener. Transm. Distrib. 1997, 144, 456-460. [CrossRef]

15. Mozaffari, S.; Henschel, S.; Soudack, A.C. Chaotic ferroresonance in power transformers. IEE Proc. Gener. Transm. Distrib. 1995, 142, 247-250. [CrossRef]

16. Milicevic, K.; Emin, Z. Initiation of Characteristic Ferroresonance States Based on Flux Reflection Model. IEEE Trans. Circuits Syst. II Express Briefs 2013, 60, 51-55. [CrossRef]

17. Chen, X.; Caputo, J.P.; Baghzouz, Y. Harmonic analysis of ferroresonance in single-phase transformers. In Proceedings of the 2012 IEEE 15th International Conference on Harmonics and Quality of Power, Hongkong, China, 17-20 June 2012; pp. 535-540.

18. Moses, P.S.; Masoum, M.A.S.; Toliyat, H.A. Impacts of Hysteresis and Magnetic Couplings on the Stability Domain of Ferroresonance in Asymmetric Three-Phase Three-Leg Transformers. IEEE Trans. Energy Convers. 2011, 26, 581-592. [CrossRef]

19. Mork, B.; Stuehm, D. Application of nonlinear dynamics and chaos to ferroresonance in distribution systems. IEEE Trans. Power Deliv. 1994, 9, 1009-1017. [CrossRef]

20. Duan, X.; Zhao, T.; Liu, J.; Zhang, L.; Zou, L. Analysis of Winding Vibration Characteristics of Power Transformers Based on the Finite-Element Method. Energies 2018, 11, 2404. [CrossRef]

21. Zeng, X.J.; Yin, X.; Chen, D.S. Ground fault protection for generator stator windings with inductance compensating based on injecting signal. Proc. CSEE 2000, 20, 51-55.

22. Zhang, Q.; Xi, K.; Chen, J.; Wang, X.; Shen, Q. Field application and analysis of the stator earth fault protection with voltage injection for large-sized generator. Autom. Electr. Power Syst. 2007, 31, 103-107. 